\title{
REVIEW
}

\section{Severe Asthma and Biological Therapy: When, Which, and for Whom}

\author{
Paola Rogliani · Luigino Calzetta (D) - Maria Gabriella Matera • \\ Rossella Laitano • Beatrice Ludovica Ritondo • Nicola A. Hanania • \\ Mario Cazzola
}

Received: October 24, 2019 / Published online: December 26, 2019

(C) The Author(s) 2019

\section{ABSTRACT}

Asthma is a heterogeneous chronic inflammatory disease of the airways that affects approximately 300 million people worldwide. About $5-10 \%$ of all asthmatics suffer from severe or uncontrolled asthma, associated with increased mortality and hospitalization, reduced quality of life, and increased health care costs. In recent years, new treatments have become available, and different asthma phenotypes characterized by specific biomarkers have been identified.

Enhanced Digital Features To view enhanced digital features for this article go to https://doi.org/10.6084/ m9.figshare.11359379.

P. Rogliani · L. Calzetta $(\bowtie) \cdot$ R. Laitano ·

B. L. Ritondo · M. Cazzola

Respiratory Unit, Department of Experimental

Medicine, University of Rome "Tor Vergata", Rome, Italy

e-mail: luigino.calzetta@uniroma2.it

M. G. Matera

Department of Experimental Medicine, University of Campania Luigi Vanvitelli, Naples, Italy

N. A. Hanania

Section of Pulmonary, Critical Care and Sleep

Medicine, Baylor College of Medicine, Houston, TX, USA
Biological drugs are currently indicated for patients with severe asthma that is not controlled with recommended treatments. They are mostly directed against inflammatory molecules of the type 2 inflammatory pathway and are effective at reducing exacerbations, maintaining control over asthma symptoms, and reducing systemic steroid use, which is associated with well-known adverse events. Although biological drugs for severe asthma have had a major impact on the management of the disease, there is still a need for head-to-head comparison studies of biologics and to identify new biomarkers for asthma diagnosis, prognosis, and response to treatment. Identifying novel biomarkers could facilitate the development of therapeutic strategies that are precisely tailored to each patient's requirements.

Keywords: Biomarkers; Biological drugs; Monoclonal antibodies; Phenotypes; Severe asthma 


\section{Key Summary Points}

Asthma is a heterogeneous chronic inflammatory airway disease that affects approximately 300 million people worldwide, with about $5-10 \%$ of all asthmatics suffering from severe or uncontrolled asthma.

This narrative review analyzes the impact of biological agents that are currently approved and under investigation in order to aid the selection by clinicians of the appropriate biological drug for the management of each severe asthma phenotype.

There is medical need for head-to-head comparison studies of biologics as well as to identify biomarkers for asthma diagnosis, prognosis, and response to treatment.

It is important to identify prognostic and therapeutic biomarkers that characterize specific phenotypes of severe asthma, as this should allow therapeutic strategies that are specifically tailored to individual patients to be devised.

Identifying novel biomarkers could facilitate the development of therapeutic strategies that are precisely tailored to each patient's requirements.

\section{INTRODUCTION}

Asthma is a heterogeneous chronic inflammatory disease of the airways characterized by chronic airway inflammation, bronchoconstriction, airway hyperresponsiveness, and mucus hypersecretion. Typical symptoms are wheezing, shortness of breath, chest tightness, and cough with variable expiratory flow limitation [1]. Asthma affects approximately 300 million people worldwide, and about $5-10 \%$ of all asthmatics suffer from severe or

uncontrolled asthma, which is associated with increased mortality and hospitalization, reduced quality of life (QoL), and increased health care costs. According to the American Thoracic Society/European Respiratory Society (ATS/ERS) Task Force, asthma is defined as severe when it "requires treatment with high dose inhaled corticosteroids (ICSs) plus a second controller (and/or systemic corticosteroids) to prevent it from becoming uncontrolled or which remains uncontrolled despite this therapy" [1].

Primary endpoints of asthma management are symptom control, fewer exacerbations, improved lung function, and minimization of the long-term adverse events (AEs) of therapies [1]. However, the widely used steps of care approach to asthma treatment is often ineffective due to the heterogeneity of asthma and the extreme variability in the response of asthma to available medications [2]. Furthermore, many patients continue to have poor symptom control and to suffer from recurrent exacerbations despite strictly adhering to therapy [3]. Improvements in our knowledge of the etiopathological mechanisms of different phenotypes and endotypes of severe asthma have led to the availability of innovative therapies in the last few years. For example, biological drugs for severe asthma, most of which are directed against molecules involved in the type 2 inflammatory pathway, modify the natural history of the disease.

The aim of this narrative review is to discuss the effects of biological drugs that are currently approved or under investigation in order to aid clinicians who are attempting to select the appropriate biological agent for managing $\mathrm{T}$ helper 2 (Th2)-high/severe asthma phenotypes. This article is based on reviews of current guidelines and literature and does not involve any studies with human participants or animals.

\section{SEVERE ASTHMA PHENOTYPES AND BIOLOGICAL THERAPY}

Asthma is a chronic airway disease that is highly heterogeneous in terms of its pathogenesis, 
clinical manifestations, severity of symptoms, and outcomes. Recently, the integration of genetics, biology, and clinical features and an improved understanding of asthma pathogenesis have led to the identification of different asthma phenotypes characterized by specific biomarkers. Two major groups of asthma phenotypes that can be distinguished based on the inflammatory pathway involved, namely Th2high and Th2-low phenotypes, have been recognized. Th2-high-related inflammation is the main characteristic of Th2-high phenotypes, together with early-onset allergic asthma and late-onset eosinophilic asthma. Neutrophilic asthma and obesity-related asthma are considered Th2-low phenotypes [4].

In allergic asthma, the allergens presented to naive $\mathrm{CD}^{+} \mathrm{T}$ cells by dendritic cells (DCs) induce differentiation into Th2 cells. In nonallergic eosinophilic asthma, respiratory epithelium-derived cytokines and chemokines such as thymic stromal lymphopoietin (TSLP), interleukin (IL)-25, and IL-33 (also called alarmins) are released in response to various harmful triggers (air pollutants, microbes, or glycolipids) [5]. Alarmins bind to the receptors on type-2 innate lymphoid cells (ILC2s). Both of these types of activated cells (Th2 cells and ILC2s) produce cytokines such as IL-4, IL-5, and IL-13, which are the principal effectors of type 2 inflammation $[6,7]$. IL-5 is the most specific trigger for eosinophils, as it drives eosinophil maturation in bone marrow, recruitment, and activation [8]. IL-4 and IL-13, which share a common receptor subchain (IL-4R $\alpha$ ), induce allergen-specific immunoglobulin (Ig) E synthesis. IgE, through its interaction with the specific receptor FceRI (expressed in different immune cells), promotes the release of mediators that are responsible for functional and structural modifications of the bronchial wall. Also, IL-13 activates epithelial inducible nitric oxide (NO) synthase, leading to increased airway NO production, periostin expression in lung epithelial cells and fibroblasts, mucus production by goblet cells, and airway smooth muscle contractility [9].

Approximately $40-50 \%$ of all patients with asthma present the early-onset allergic phenotype. These patients develop the disease during childhood and are characterized by atopy, polysensitization to allergens, high total IgE, high fractional exhaled NO (FeNO) levels, increased sputum and blood eosinophils, and increased airway periostin. High levels of IgE, FeNO, eosinophils, and airway periostin are considered biomarkers of Th2-high-related inflammation. Some of these biomarkers, such as eosinophils and $\mathrm{FeNO}$, are also associated with the late-onset eosinophilic asthma phenotype $[4,10]$. Interestingly, eosinophils and FeNO are considered valid non invasive biomarkers of type 2 asthma, as they yield acceptable detection accuracy. However, their levels can be influenced by infections, by exposure to allergens and steroids, and by age, height, sex, and smoking habit [11]. In any case, since sputum eosinophil count of $\geq 3 \%$ is well correlated with type 2 asthma, it continues to generate considerable clinical research interest [12]. Approximately $25 \%$ of all patients with severe asthma present the lateonset eosinophilic phenotype [13], which is often characterized by a nonsignificant response to treatment with corticosteroids (CSs). This evidence indicates that the Th2 process is separate from the underlying early-onset allergic phenotype, and that blood/sputum eosinophilia can be used as a biomarker to select patients who should be responsive to anti-eosinophilic therapies, including anti-IL-5 [14]. Moreover, adult eosinophilic asthma is sometimes associated with chronic sinusitis and nasal polyps in patients without a clear history of atopy.

Th2-low phenotypes are characterized by a prevalent Th1- and Th17-driven immunity, neutrophilic inflammation, infection, and oxidative stress. These phenotypes are also associated with obesity and systemic inflammation, including increased levels of different cytokines such as tumor necrosis factor alpha (TNF- $\alpha$ ), IL-6, and leptin [15]. Biological therapy of Th2-low asthma phenotypes will not be discussed in the present narrative review.

Increased knowledge of molecular pathways and the characterization of severe asthma phenotypes may help to drive the use of novel biological therapies that have been approved or are under investigation. Biological therapy has been demonstrated to be effective at reducing asthma exacerbations, maintaining control over 


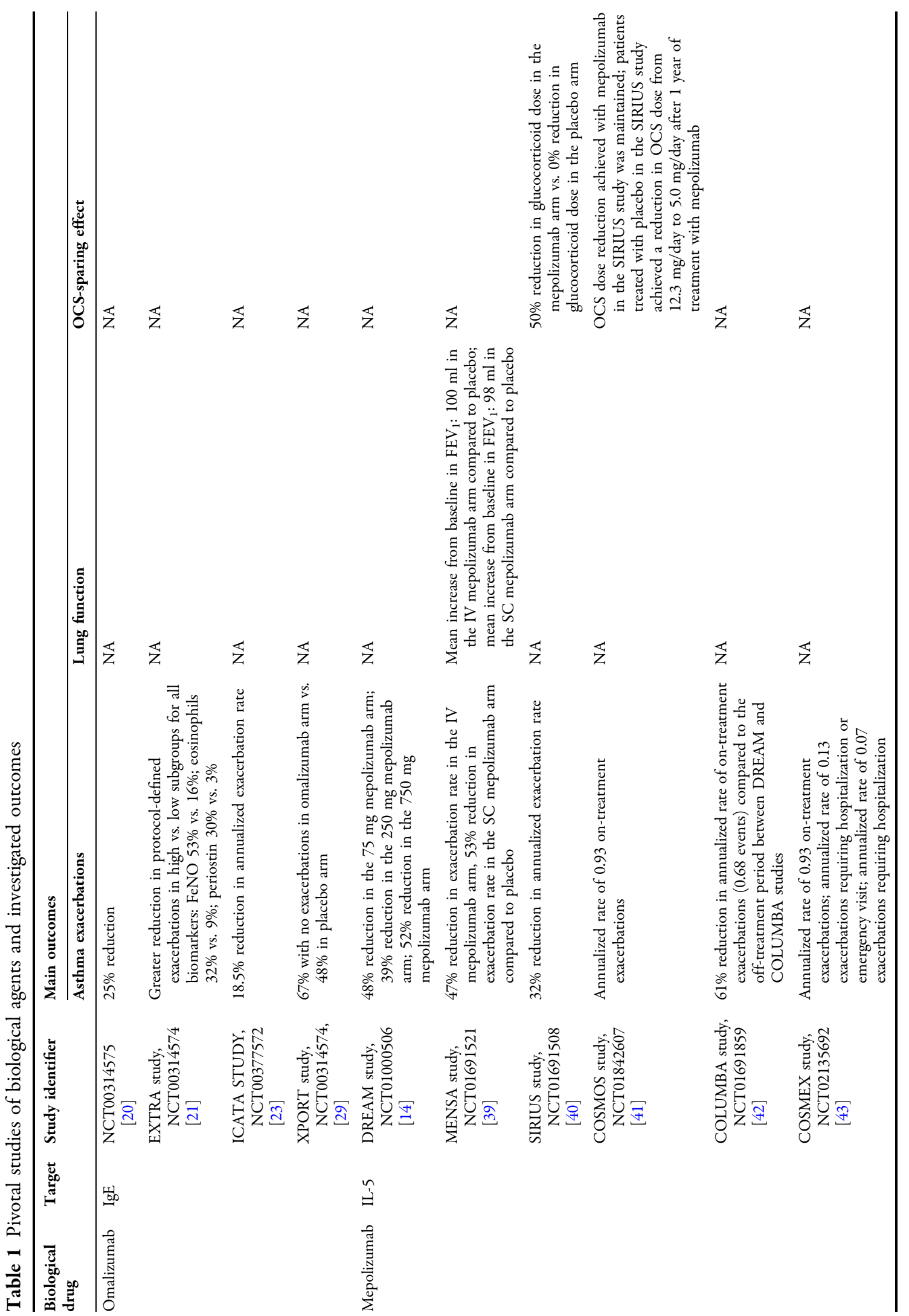




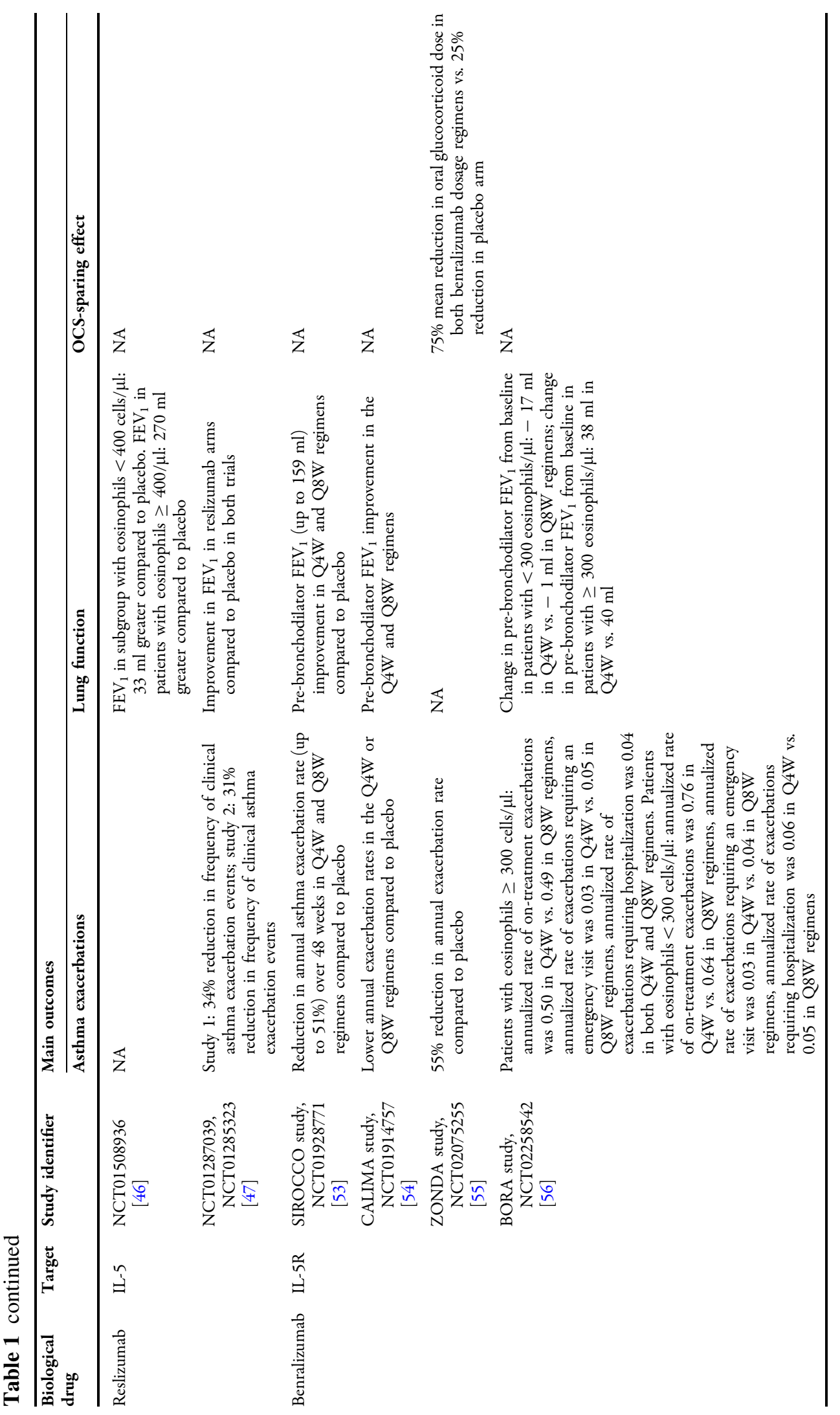




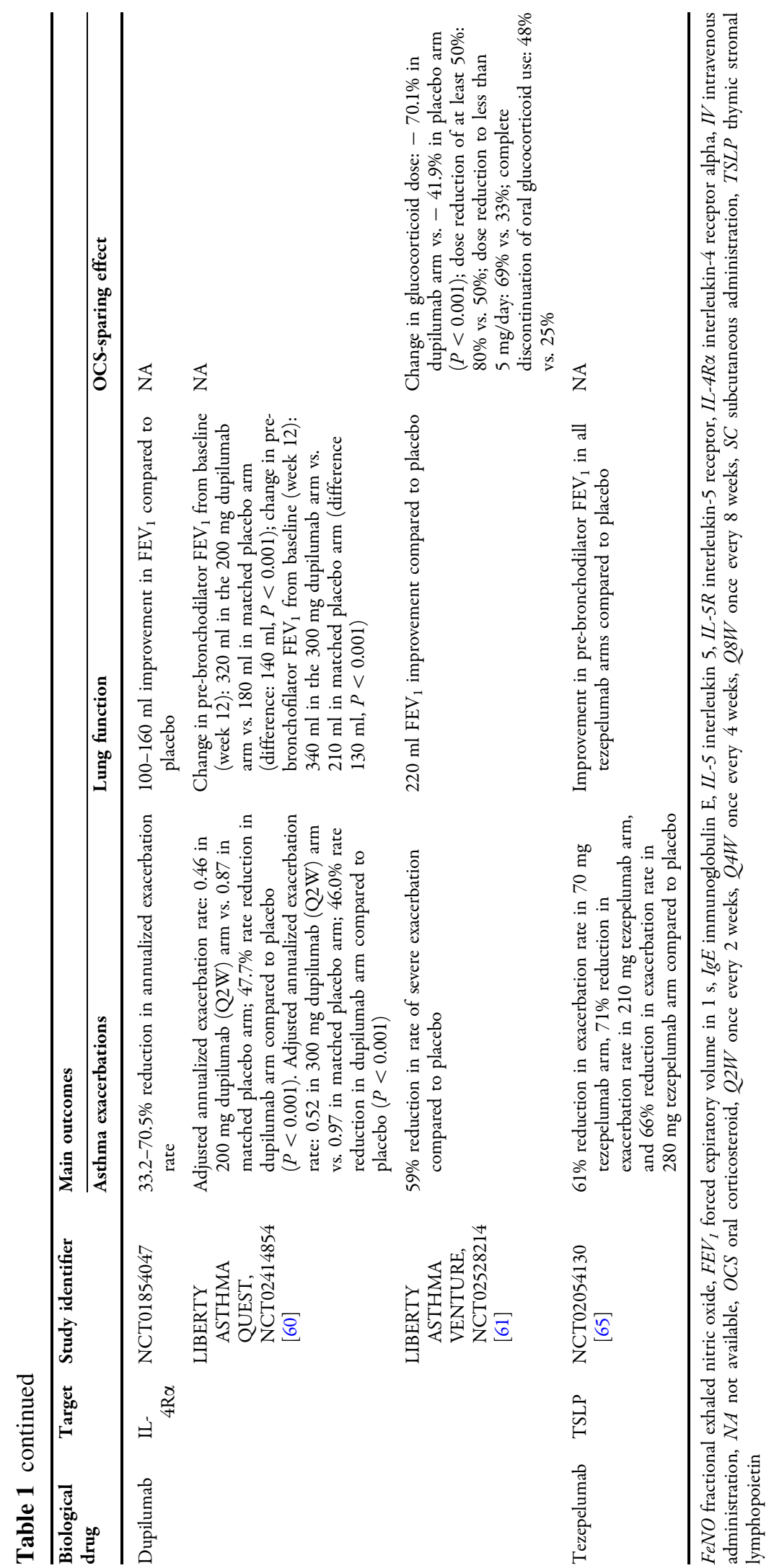


asthma symptoms, and reducing the need for steroid bursts while preventing the well-known adverse events associated with steroid use. Pivotal studies of the utilization of biological agents in patients with severe asthma are reported in Table 1, along with results concerning the main outcomes investigated.

\section{MONOCLONAL ANTIBODIES IN SEVERE ASTHMA}

\section{Omalizumab}

Omalizumab was the first biological drug to be approved by the US Food and Drug Administration (FDA) and European Medicines Agency (EMA) for the treatment of severe asthma $[16,17]$. It is a recombinant humanized monoclonal antibody (mAb) that selectively binds circulating IgE, thus decreasing IgE levels in blood [18]. According to the recommendations of the Global Initiative for Asthma (GINA) and the EMA and FDA, omalizumab is indicated in adults and children $\geq 6$ years old with IgE-mediated moderate-to-severe persistent allergic asthma that remains uncontrolled despite GINA step 4 treatment, high levels of blood IgE, and at least a sensitization to a perennial allergen [1]. Omalizumab is administered subcutaneously every 2-4 weeks according to the baseline total IgE level and body weight. Although the European label for omalizumab clarifies that the drug is suitable for long-term use, patients should be re-evaluated after 16 weeks of treatment to assess the efficacy of the drug before continuing with omalizumab therapy [19].

In a phase 3 randomized controlled trial (RCT) performed by Hanania et al. (NCT00314575), omalizumab reduced the rate of asthma exacerbation by $25 \%$ compared with placebo, improved the mean Asthma QoL Questionnaire score (AQLQS), reduced the daily as-needed rescue medication administered, and decreased the mean Asthma Symptom Score [20]. The EXTRA study (NCT00314574), a post hoc analysis of Hanania's RCT [20], grouped patients according to Th2 biomarker levels (high/low FeNO, blood eosinophils, and serum periostin levels) and demonstrated that the reduction in exacerbation rate was greater in the groups with high biomarker levels [21]. This suggests that patients with high levels of Th2 biomarkers may receive a greater benefit from omalizumab therapy [21]. Other data showed that patients with at least 300 eosinophils/ $\mu$ l obtained a better response from omalizumab treatment, with an up to $60 \%$ decrease in asthma exacerbations compared to patients with less than 300 eosinophils/ $\mu \mathrm{l}$ [22].

In the Inner-City Anti-IgE Therapy for Asthma (ICATA) phase 4 RCT (NCT00377572), omalizumab improved asthma control, reduced the use of as-needed rescue medication, and abolished seasonal exacerbation peaks in innercity children, adolescents, and young adults (6-20 years old) with persistent allergic asthma compared with placebo [23].

It is well known that viral respiratory infections are a major cause of asthma exacerbations. Indeed, it has been demonstrated that induced airway hyperresponsiveness could be the result of bronchoconstriction caused by neuraminidase via the inhibition of prejunctional muscarinic receptors ( $\mathrm{M}_{2}$ subtypes) [24]. Thus, it seems that the ability of omalizumab to reduce circulating IgE and the expression of the highaffinity IgE receptor FceRI in DCs may attenuate the allergic response while strengthening the antiviral immune response, ultimately preventing exacerbations [25]. Further studies, including a meta-analysis, showed that treatment with omalizumab reduces the number of emergency department visits and the need for systemic steroid bursts [26-28].

The Xolair Persistency of Response After Long-Term Therapy (XPORT) long-term phase 4 RCT (NCT01125748) demonstrated that longterm therapy with omalizumab results in a persistent improvement in symptom control and a reduced risk of exacerbations. This study also showed that discontinuation of omalizumab is associated with increased circulating IgE levels and basophil expression of FceRI [29]. However, an open prospective study demonstrated that the effects of 6 years of omalizumab may persist for at least 4 years after the discontinuation of therapy in $60 \%$ of patients [30].

In the phase 4 Real-life Effectiveness of Omalizumab Therapy (REALITY) study (NCT01776177), 
a single-center, retrospective, observational, longterm, real-life investigation demonstrated that overall visit adherence upon treatment with omalizumab was $78 \%$, although the adherence rate decreased by $20 \%$ every year [31]. The response to therapy rate was assessed via the Standardized Measure to Assess Response to Therapy (SMART) tool, according to which the response rate increased over time, with the highest level achieved after 5 years of treatment (85\%) [31]. Omalizumab was well tolerated, with no serious AEs reported [31].

The phase 4 Real-life Prospective Observational Study to Evaluate Predictors of Clinical Effectiveness in Response to Omalizumab (PROSPERO; NCT01922037) proved that treatment with omalizumab reduces exacerbation and hospitalization rates and improves asthma symptom control irrespective of blood eosinophils and FeNO status at baseline. Indeed, these results contrast with those reported by Hanania et al. (NCT00314575), indicating that blood eosinophil count remains a controversial biomarker of omalizumab efficacy [32].

In the PROSPERO study, the frequency of serious AEs (SAEs) was $11.2 \%$ in both adolescents and adults. The most common serious AEs were asthma (3.2\%), pneumonia (1.4\%), chronic obstructive pulmonary disease $(0.5 \%)$, anaphylactic events $(0.5 \%)$, and pulmonary embolism and status asthmaticus (0.4\%). All anaphylactic events were of moderate severity and related to omalizumab, and all occurred in the adult population. Seven fatal adverse events occurred, none of which was related to omalizumab [32].

\section{Mepolizumab}

Mepolizumab is a $\mathrm{mAb}$ that is directed against IL-5 and has been approved as an add-on treatment for patients $\geq 6$ years old (EMA) or $\geq 12$ years old (FDA) with severe eosinophilic asthma that remains uncontrolled despite GINA step 4 therapy [14, 33-35]. Mepolizumab is indicated in patients who have a blood eosinophil count of $\geq 150$ cells/ $\mu$ l at the moment of first administration or $\geq 300$ cells/ $\mu \mathrm{l}$ in the past year and have had $\geq 2$ asthma exacerbations requiring steroid bursts in the previous year $[34,35]$. In agreement with guidelines from the National Institute for Health and Clinical Excellence (NICE) in the UK, mepolizumab is indicated in patients with a blood eosinophil count of $\geq 300$ cells/ $\mu \mathrm{l}$ or more in the previous 12 months and $\geq 4$ asthma exacerbations requiring systemic steroids or continuous oral corticosteroids (OCSs) equivalent to (at least) prednisolone $5 \mathrm{mg} /$ day over the previous 6 months [36]. Mepolizumab is administered subcutaneously at a fixed dose of $100 \mathrm{mg}$ every 4 weeks.

Recommendations from international guidelines regarding the duration of treatment to assess the efficacy of mepolizumap are not consistent. For instance, the GINA document indicates that a 4-month trial should be adequate to assess the effectiveness of mepolizumab in patients with severe asthma [37], whereas the NICE guidelines suggest that mepolizumab should be stopped after 12 months of treatment if the asthma is not adequately controlled, or the treatment can be continued while assessing responsiveness to the drug each year [38].

In the DREAM (Dose Ranging Efficacy and Safety with Mepolizumab) phase 2 RCT (NCT01000506), mepolizumab significantly reduced the exacerbation rate and time to first exacerbation compared to placebo in patients with severe eosinophilic asthma with $\geq 300$ blood eosinophils/ $\mu$ l or sputum eosinophils $\geq 3 \%(P \leq 0.001$ for all tested doses: 75,250 , and $750 \mathrm{mg}$ ). Enhanced mepolizumab efficacy was detected in patients with an increased blood eosinophil count at baseline and a relatively high number of prior exacerbations [14].

In the MENSA (Mepolizumab as Adjunctive Therapy in Patients with Severe Asthma) phase 3 RCT (NCT01691521), mepolizumab that was administered either intravenously (75 mg) or subcutaneously $(100 \mathrm{mg})$ significantly reduced (by $\approx 50 \%$ ) the asthma exacerbation rate in patients with severe eosinophilic asthma compared to placebo. Mepolizumab also improved the forced expiratory volume in $1 \mathrm{~s}\left(\mathrm{FEV}_{1}\right)$ $(P<0.05$ vs. placebo), the QoL assessed via the St. George's Respiratory Questionnaire (SGRQ), and asthma control assessed via the 5-item 
Asthma Control Questionnaire (ACQ-5) (both $P<0.001$ vs. placebo) [39].

In the SIRIUS (Steroid Reduction with Mepolizumab Study) phase 3 RCT (NCT01 691508), which included patients with severe asthma requiring daily maintenance OCS therapy, mepolizumab reduced the dose of OCSs required by $50 \%$ while maintaining asthma control and reducing the exacerbation rate by $32 \%$ compared to placebo $(P<0.05)$ [40].

According to long-term efficacy and safety data on mepolizumab from the COSMOS study (NCT01842607), an extension study of the MENSA and SIRIUS RCTs, patients who were previously treated with mepolizumab maintained a reduced exacerbation rate whereas those who were in the placebo arms in the previous studies showed improvement at the same endpoints after mepolizumab administration [41]. Mepolizumab presented a positive long-term safety profile. No increase in the $\mathrm{AE}$ rate was observed over the study period or when compared with previous placebo-controlled trials. The most common AEs were respiratory tract infection (67\%), headache (29\%), worsening of the asthma (27\%), bronchitis (21\%), and injection-site reactions (12\%). Systemic allergic/ hypersensitive reactions were recorded in $2 \%$ of patients, and $<1 \%$ of patients experienced a nonallergic systemic reaction. No reports of mepolizumab-related anaphylaxis were reported. On-treatment opportunistic infections (7\%) were also reported, none of which were parasitic infections. Malignancies were reported in $2 \%$ of patients [41].

The COLUMBA study (NCT01691859), an open-label, long-term extension study in patients who participated in the DREAM study, confirmed the long-term efficacy of mepolizumab at reducing the exacerbation rate, ACQ-5 and blood eosinophil counts, and the safety profile of this $\mathrm{mAb}$ [42].

The COSMOS Extension (COSMEX) study (NCT02135692) found that the long-term administration of mepolizumab was well tolerated and provided persistent clinical benefits in patients suffering from life-threatening or very severe eosinophilic asthma [43]. The annualized exacerbation rate was low (0.93 event/year), and patients who had previously participated in the
MENSA [39] and COSMOS [41] studies reported sustained reductions in the exacerbation rate and daily OCS use upon long-term treatment with mepolizumab [43]. Conversely, patients who interrupted therapy with mepolizumab for $>3$ months between the COSMOS and the COSMEX studies reported an improvement in ACQ score and lung function as well as a reduction in eosinophil count when treatment with mepolizumab was restarted [43]. Twentyfive percent of the total population analyzed reported serious AEs, and $0.9 \%$ of those AEs were considered to be related to the treatment [43].

\section{Reslizumab}

Reslizumab is a mAb directed against IL-5, so it has the same mechanism of action as mepolizumab. It has been approved by the EMA and FDA as an add-on treatment for adult patients ( $\geq 18$ years old) with severe eosinophilic asthma that remains uncontrolled despite therapy with high-dose ICSs plus another controller. Reslizumab is indicated in patients with $\geq 400$ eosinophils/ $\mu$ l and $\geq 3$ asthma exacerbations in the past 12 months [36, 44, 45]. Reslizumab is administered intravenously every 4 weeks at a dose of $3 \mathrm{mg} / \mathrm{kg}$.

Corren et al. [46], in a phase 3 RCT designed to establish the eosinophil threshold that should be used to select patients for reslizumab treatment (NCT01508936), demonstrated that treatment led to significant improvements in lung function, symptom control, rescue medication use, and forced vital capacity (FVC) in patients with $\geq 400$ eosinophils/ $\mu$ l. Two further phase 3 RCTs (NCT01287039, NCT01285323) demonstrated that reslizumab administered as an add-on therapy to ICSs with or without other controllers significantly reduced the asthma exacerbation rate compared to placebo (34\% and $31 \%$ respectively; both $P<0.0001$ ) [47].

An open-label extension study (NCT0129 0887) conducted by Murphy et al. [48] evaluated the safety and efficacy of reslizumab for up to 24 months and demonstrated that reslizumab-experienced patients and reslizumabnaïve patients had improved lung function and 
asthma control throughout the study period. The most frequently reported AEs in both reslizumab-experienced and reslizumab-naïve patients were asthma worsening ( $28 \%$ vs. $46 \%)$, nasopharyngitis (14\% vs. $14 \%)$, upper respiratory tract infection ( $10 \%$ vs. $9 \%)$, sinusitis $(8 \%$ vs. $6 \%)$, headache ( $7 \%$ vs. $11 \%)$, and local administration-related AEs $(<1 \%)$. Anaphylaxis and parasitic and opportunistic infections were not reported. Similar levels of anti-reslizumab antibody were detected in patients in both groups at baseline (4\%) and during treatment (5\%).

\section{Benralizumab}

Benralizumab is a humanized afucosylated $\mathrm{mAb}$ against IL-5 receptor $\alpha$ (IL-5R $\alpha)$ that induces eosinophil apoptosis through the mechanism of antibody-dependent cell-mediated cytotoxicity (ADCC) involving natural killer cells, inducing peripheral blood eosinophil depletion $[49,50]$. It is approved as an add-on treatment for inadequately controlled severe eosinophilic asthma in adult patients (EMA) and subjects aged $\geq 12$ years (FDA) with $\geq 300$ blood eosinophils/ $\mu \mathrm{l}[51,52]$. A $30 \mathrm{mg}$ dose of benralizumab is administered subcutaneously every 4 weeks for the first 3 months and then every 8 weeks.

In two large phase 3 RCTs, SIROCCO (NCT01928771) and CALIMA (NCT01914757), which were carried out in patients with severe asthma and a high blood eosinophil count $(\geq 300$ cells $/ \mu \mathrm{l}), \quad 30 \mathrm{mg}$ of benralizumab administered as an add-on therapy every 4 weeks or every 8 weeks were found to significantly reduce the asthma exacerbation rate (by up to $51 \% ; P<0.0001$ ) and to improve $\mathrm{FEV}_{1}$ (by up to $159 \mathrm{ml}$ ) and the blood eosinophil count compared with the control $[53,54]$.

In the ZONDA phase 3 RCT (NCT02075255), OCS doses were reduced by $75 \%$ in the benralizumab arm, compared with $25 \%$ in the placebo arm, over 28 weeks of treatment. The annual exacerbation rate was reduced by $55 \%$ compared to placebo, but there was no change in $\mathrm{FEV}_{1}[55]$.

In an extension study (NCT02258542), Busse et al. [56] demonstrated that benralizumab administered for 2 years maintained its efficacy and had a safety and tolerability profile similar to that observed over 1 year in the SIROCCO and CALIMA RCTs. The most common AEs were viral upper respiratory tract infections (14-16\%; mostly bacterial pneumonia) and worsening asthma (7-10\%). No cases of helminth infection were reported, and rates of hypersensitivity AEs were similar across the study groups. Positive anti-drug antibody responses were detected in $8-11 \%$ of patients receiving benralizumab for a second year, but a slight decrease in eosinophil-depleting activity due to high titers of antidrug antibodies was noted at very low trough concentrations of benralizumab [56].

\section{Dupilumab}

Dupilumab is a humanized $\mathrm{mAb}$ directed against the $\alpha$ chain of the IL- 4 receptor (IL- $4 \mathrm{R} \alpha$ ), which is common to both IL- 4 and IL-13, so this drug is able to inhibit the signaling of both ILs. Dupilumab is approved by the FDA as an add-on maintenance therapy in patients with moderateto-severe asthma who are aged $\geq 12$ years and have an eosinophilic phenotype or OCS-dependent asthma, and by the EMA as an add-on maintenance treatment for severe asthma with type 2 inflammation characterized by raised blood eosinophils and/or raised FeNO in adolescents aged $\geq 12$ years that is inadequately controlled with high-dose ICS plus another medicinal product for maintenance treatment.

Dupilumab is administered subcutaneously at an initial dose of $400 \mathrm{mg}$ (two $200 \mathrm{mg}$ injections) followed by $200 \mathrm{mg}$ every 2 weeks, or at an initial dose of $600 \mathrm{mg}$ (two $300 \mathrm{mg}$ injections) followed by $300 \mathrm{mg}$ every 2 weeks. According to the EMA, a starting dose of $600 \mathrm{mg}$ is recommended only for patients with OCSdependent asthma or moderate-to-severe atopic dermatitis (for which dupilumab is also indicated) [57]. The FDA approved both regimens (400/200 mg and 600/300 mg) without specific indications, except for patients with OCS-dependent asthma or moderate-to-severe atopic dermatitis, for whom an initial dose of $600 \mathrm{mg}$ administered subcutaneously is indicated [58]. 
In a phase 2 dose-ranging study (NCT01 854047), Wenzel et al. [59] allocated patients with severe uncontrolled asthma to four groups with different dosing and timing schemes $(200 \mathrm{mg}$ every 4 weeks, $300 \mathrm{mg}$ every 4 weeks, $200 \mathrm{mg}$ every 2 weeks, and $300 \mathrm{mg}$ every 2 weeks). The dupilumab groups showed improved lung function and patient-reported outcomes as well as fewer severe exacerbations compared with placebo. Although these results were observed in the overall population, the subgroup with at least 300 eosinophils/ $\mu$ l showed the greatest reduction in the annualized severe exacerbation rate and improvement in $\mathrm{FEV}_{1}$ [59].

In the LIBERTY ASTHMA QUEST phase 3 RCT (NCT02414854) conducted in patients aged $\geq 12$ years old with uncontrolled asthma, dupilumab significantly reduced asthma exacerbations by $\approx 50 \%$ and improved $\mathrm{FEV}_{1}$. Two dupilumab dosing schemes, $200 \mathrm{mg}$ and $300 \mathrm{mg}$ every 2 weeks, were tested [60]. In this study, the safety profile was favorable. The frequency of AEs was similar across the intervention groups (81.0\%). Injection-site reaction was the most frequent $\mathrm{AE}(15.2 \%$ in the lower-dose dupilumab group vs. $5.4 \%$ in the matched placebo group; $18.4 \%$ in the higher-dose dupilumab group vs. $10.3 \%$ in the matched placebo group). An eosinophil count of $>3000$ per cubic millimeter during the intervention period was considered to indicate an $\mathrm{AE}$ (AE rate: $1.2 \%$ in the dupilumab groups combined and $0.3 \%$ in the placebo groups combined). SAEs (worsening of hypereosinophilia and chronic eosinophilic pneumonia) were suffered by two patients in the dupilumab groups who showed increased blood eosinophils. Conjunctivitis was also observed during the study period, with no meaningful difference in rate between the study groups. The most frequent SAE was pneumonia (suffered by $8.2 \%$ of patients receiving dupilumab and $8.4 \%$ of patients receiving placebo). Persistent anti-drug antibody responses were reported, but they had no meaningful effect on drug safety or efficacy.

In the LIBERTY ASTHMA VENTURE phase 3 RCT (NCT02528214), Rabe et al. [61] demonstrated that dupilumab is effective at reducing the need for OCSs while maintaining asthma control, reducing asthma exacerbations (by
59.3\%), and improving lung function. The frequency of AEs during the trial period was similar in the two groups $(62 \%$ in the dupilumab group and $64 \%$ in the placebo group).

In a recent post-hoc analysis of a phase 2 study (NCT01854047), dupilumab produced a significant and clinically meaningful improvement in asthma symptom control as assessed via ACQ-5, AM/PM Asthma Symptoms Score, QoL, and productivity in an intention-to-treat population who received the drug administered at a dose of $200 / 300 \mathrm{mg}$ every 2 weeks [62]. Another post-hoc analysis of the same study (NCT01854047) indicated that dupilumab $200 \mathrm{mg}$ and $300 \mathrm{mg}$ administered every 2 weeks significantly $(P<0.05)$ reduced the rate of severe exacerbations and significantly $(P<0.05)$ improved lung function, asthma control, and QoL compared to placebo, regardless of the exacerbation history of the patient [63].

According to a post hoc analysis of the LIBERTY ASTHMA QUEST study (NCT02414854), dupilumab administered at $200 \mathrm{mg}$ and $300 \mathrm{mg}$ significantly $(P<0.001)$ reduced the rate of severe exacerbations in uncontrolled, moderateto-severe asthma patients with evidence of allergic asthma ( $-36.9 \%$ and $-45.5 \%$, respectively) and in patients without an allergic component $(-60.0 \%$ and $-44.6 \%$, respectively) [64]. In patients with or without allergic asthma, both doses significantly $(P<0.01)$ improved asthma control as well as lung function compared to placebo [64]. Dupilumab $200 \mathrm{mg}$ and $300 \mathrm{mg}$ also significantly reduced total serum IgE compared to placebo in patients with asthma with or without an allergic component [64].

\section{BIOLOGICAL DRUGS UNDER DEVELOPMENT}

Tezepelumab is a humanized $\mathrm{mAb}$ that is under development. It binds TSLP, preventing the interaction of TSLP with its receptor, which is expressed on different immune cells of the type 2 inflammatory cascade. Corren et al. [65] conducted a phase 2 RCT (NCT02054130) that aimed to compare tezepelumab administered at $70 \mathrm{mg}$ and $210 \mathrm{mg}$ every 4 weeks and 
tezepelumab administered at $280 \mathrm{mg}$ every 2 weeks with placebo. All dosage regimens showed statistically significant reductions in the annualized asthma exacerbation rate and improvements in the pre-bronchodilator $\mathrm{FEV}_{1}$ compared with placebo. Reductions in the investigated Th2 biomarkers (eosinophils, FeNO, and IgE) in patients treated with tezepelumab suggest that this $\mathrm{mAb}$ affects the IL-4, IL-5 and IL-13 pathways [65].

The drug-related SAEs observed in the RCT were pneumonia and stroke (which occurred in the same patient in the low-dose tezepelumab group) and Guillain-Barré syndrome (in the medium-dose tezepelumab group). Neither investigational product-related anaphylactic reactions nor the identification of neutralizing antibodies were reported [65].

Several studies that aim to evaluate the safety, tolerability, and efficacy profile of tezepelumab in adult patients with severe uncontrolled asthma are ongoing (CASCADE, NCT03688074; DIRECTION, NCT03927157; NAVIGATO, NCT03347279). A further phase 3 RCT will evaluate the glucocorticoid sparing effect of tezepelumab in adults with OCS-dependent asthma (SOURCE, NCT03406078).

\section{DISCUSSION}

The treatment approach for severe asthma has changed significantly during the past decade. Effective identification of specific biomarkers for severe asthma has become the basis for biomarker-related personalized medicine that has replaced the conventional strategy based on nonspecific drugs such as corticosteroids and bronchodilators-the so-called blockbuster drugs. The characterization of molecular targets has allowed the identification of patients with severe asthma who would benefit from specific biological treatments. Nevertheless, the class of biological agents that represent the best therapeutic option for patients with overlapping phenotypes is still unclear. Therefore, there is a need for further discriminatory biomarkers that can allow better patient selection and can be used to predict the response of the patient to targeted therapy. Furthermore, there is a lack of direct comparisons between currently approved biological therapies. Thus, head-to-head RCTs and further network meta-analyses performed according to the Preferred Reporting Items for Systematic Reviews and Meta-Analyses Protocols (PRISMA-P) and registered in the International Prospective Register of Systematic Reviews (PROSPERO) are needed to help clinicians to better identify the best biological therapy for each severely asthmatic patient [66].

Before starting treatment with a biological agent, it is necessary to correctly diagnose severe asthma and exclude possible confounding conditions that mimic asthma symptoms, namely chronic obstructive pulmonary disease (COPD), bronchiectasis, intermittent laryngeal obstruction (ILO), and hypersensitivity pneumonitis [67]. Comorbidities should also be assessed and eventually treated. The most frequent comorbidities associated with asthma include gastroesophageal reflux disease, aspiration, rhinosinusitis, obstructive sleep apnea, cardiovascular comorbidities, ILO, and infections [68].

The characterization of etiopathogenetic pathways defining the aspects of severe asthma has allowed the identification of specific biomarkers for specific phenotypes. Prognostic and therapeutic information can be obtained by focusing on these specific molecular targets. This approach may facilitate the effective treatment of this complex and heterogeneous disorder. The recent approval of novel biological agents has definitely changed the natural history of severe Th2-high asthma. Conversely, targeting the Th2 pathway in nonphenotyped patients seems to be barely effective.

In the GINA recommendations, biological therapy is suggested in patients with severe asthma who show typical biomarkers of type 2 airway inflammation. Currently recognized Th2-high asthma phenotypes include early- and late-onset forms of asthma. The early-onset allergic asthma phenotype is characterized by atopy, polysensitization to allergens, a high total IgE, high FeNO levels, high sputum and blood eosinophil counts, and increased airway periostin. Late-onset eosinophilic asthma is often characterized by CS treatment refractoriness and an association with chronic sinusitis 
and nasal polyps. Blood eosinophils and FeNO are considered valid noninvasive alternative biomarkers to the detection of sputum eosinophil counts of $\geq 3 \%$.

In order to identify the most effective and appropriate biological therapy to treat severe asthma, it is necessary to consider the therapeutic indications reported by international agencies, namely the EMA and FDA, as well as biomarkers (as predictors of response), although their role is often controversial. In this respect, Table 2 summarizes the indications for currently approved biological therapies for severe asthma treatment in terms of patient age, disease characteristics, posology, the main benefits, and the most common AEs, in agreement with the relevant EMA and FDA documents.

For patients with allergic non-eosinophilic severe asthma, high levels of blood IgE, and at least a sensitization to a perennial allergen, omalizumab should be considered the firstchoice biological treatment. Conversely, for patients with eosinophilic nonallergic severe asthma, it is reasonable to add an anti-IL-5 biological agent to the standard therapy. AntiIL- $4 \mathrm{R} \alpha$ is the treatment for severe eosinophilic type 2 asthma or patients requiring maintenance OCS [37].

Due to a lack of head-to-head comparison trials, there are currently no recommendations for choosing among all of the currently available biologics that target the IL-5 pathway. Therefore, despite being limited by differences in study design, several network meta-analyses have been conducted. In this respect, a matching-adjusted indirect comparison indicated that benralizumab and mepolizumab have similar efficacy profiles [69]. A network meta-analysis suggested that reslizumab could be more effective than benralizumab in patients with moderate-to-severe eosinophilic asthma, a high blood eosinophil count, and two or more exacerbations in the previous year [70]. Another indirect treatment comparison showed that, compared to reslizumab and benralizumab, mepolizumab reduced the risk of asthma exacerbations and improved disease control regardless of the blood eosinophil threshold [71]. In an arm-based network meta-analysis that aimed to assess the effects of monoclonal antibodies on the rate of asthma exacerbation, there was no significant difference between the investigated agents [72]. Conversely, the results of another quantitative synthesis indicated that, although all current mAbs were effective at reducing the risk of exacerbation and improving $\mathrm{FEV}_{1}$ compared to placebo, only dupilumab was significantly more effective than omalizumab at reducing the risk of exacerbation, and there was no difference between mepolizumab, reslizumab, benralizumab, and dupilumab [73]. Interestingly, dupilumab was also found to be significantly more effective than omalizumab, mepolizumab, and benralizumab at improving $\mathrm{FEV}_{1}$, whereas omalizumab, mepolizumab, reslizumab, and benralizumab yielded similar improvements in $\mathrm{FEV}_{1}$ [73].

According to the GINA recommendations, a 4-month trial should be conducted to assess asthma control. In the case of failed asthma control, it is possible to attempt to switch to a different type- 2 targeted biological drug if the patient is eligible. Currently, only a few studies have been conducted on biological drug switching in patients with severe asthma. One of these, a 24-week prospective, multicenter, open-label, single-group, self-controlled study, showed that reslizumab significantly improved asthma control in patients with severe eosinophilic asthma and a poor response to omalizumab [74]. In the OSMO study, a multicenter, open-label, single-arm, 32-week trial, patients with severe asthma uncontrolled by omalizumab showed an improvement in asthma control after switching to mepolizumab [75]. Interestingly, this result was confirmed by real-world evidence [76]. Preliminary findings also suggest that that in patients treated with mepolizumab who had poor asthma symptom control, switching to benralizumab led to improved QoL scores and reduced OCS maintenance doses [77]. Moreover, two triple-switch case reports indicate that patients show long-term responsiveness to mepolizumab after failed omalizumab therapy and bronchial thermoplasty [78]. However, how and when to switch from one biological drug to another and the treatment time at which the patient should be judged to be either a responder or nonresponder to therapy are yet to be adequately established. 


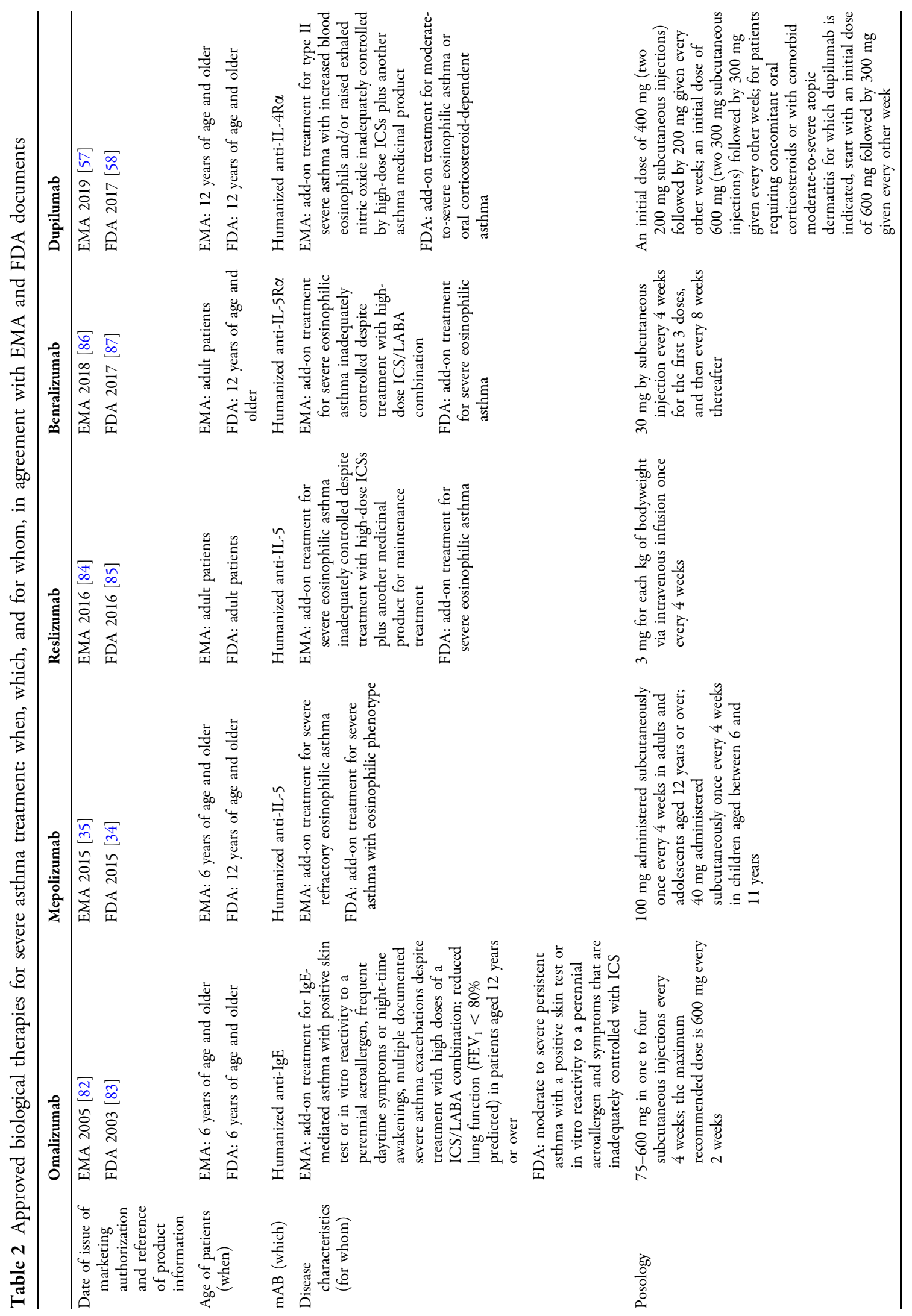




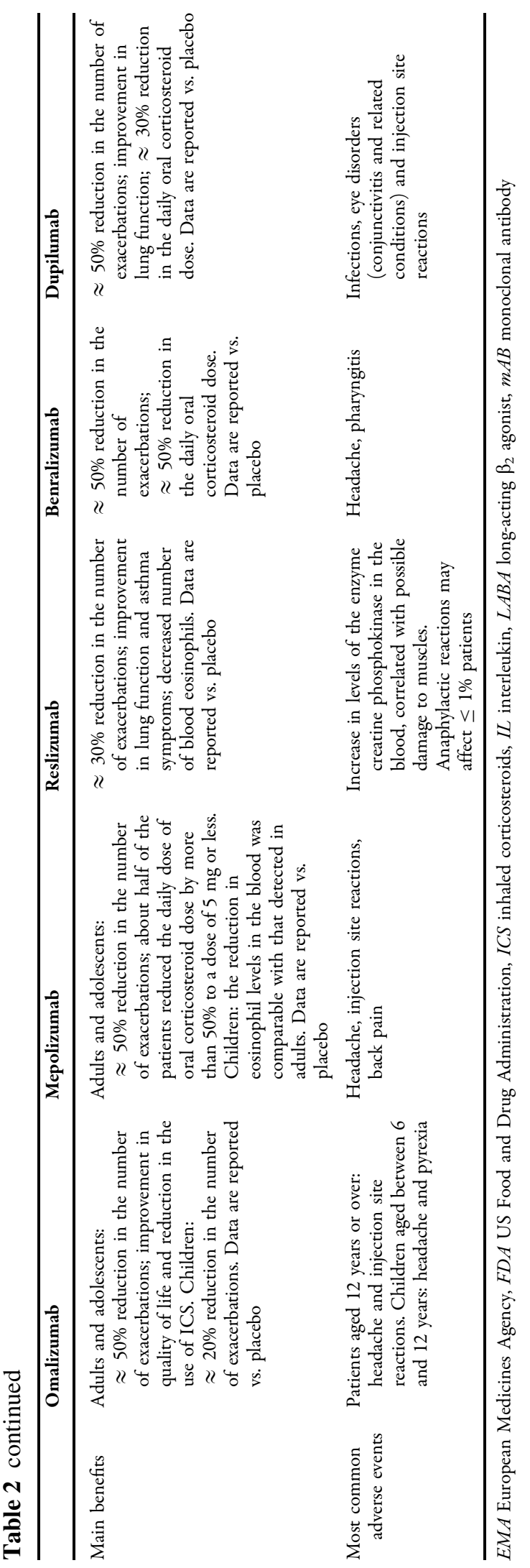

Although a withdrawal from biological therapy could be attempted after at least 12 months of treatment to check whether asthma symptom control has been achieved with medium-dose ICS add-on therapy, there is currently limited evidence concerning the actual feasibility of biologic therapy cessation $[29,43]$.

Moreover, in patients with severe asthma that is uncontrolled despite receiving add-on therapy with a biologic agent, the use of combination biological therapy could be considered. However, the efficacy and safety profile of such a combination therapy in patients eligible for multiple mAbs has not been carefully studied; relevant data originate mainly from case reports [79].

Clinical trials of biological agents directed against IL-6, IL-17, or IL-33 in patients with Th2-low asthma phenotypes are ongoing, but current knowledge suggests that these subjects should be treated with chronic macrolide, bronchial thermoplasty, or imatinib [80]. Although important advances have been made, efforts are still needed to identify useful biomarkers for Th2-low severe asthma phenotypes and to define appropriate therapies for these patients.

\section{CONCLUSIONS}

The use of biological agents has revolutionized the management of severe asthma. Nevertheless, many patients with asthma remain inadequately controlled. Thus, further effort is needed to identify other potential molecular targets that could be used as prognostic and therapeutic biomarkers, as this will facilitate therapeutic strategies that are precisely tailored to each patient's requirements [81].

\section{ACKNOWLEDGEMENTS}

Funding. This study was supported by institutional funds (1010107CTBOE16 University of Rome "Tor Vergata"). No funding was received for the publication of this study. 
Authorship. All named authors meet the International Committee of Medical Journal Editors (ICMJE) criteria for authorship for this article, take responsibility for the integrity of the work as a whole, and have given their approval for this version to be published.

Disclosures. Paola Rogliani has participated as a lecturer and advisor in scientific meetings and courses under the sponsorship of Almirall, AstraZeneca, Biofutura, Boehringer Ingelheim, Chiesi Farmaceutici, GlaxoSmithKline, Menarini Group, Mundipharma, and Novartis. Her department was funded by Almirall, Boehringer Ingelheim, Chiesi Farmaceutici, Novartis, and Zambon. Rossella Laitano and Beatrice Ludovica Ritondo have nothing to disclose. Maria Gabriella Matera has participated as a lecturer and advisor in scientific meetings and courses under the sponsorship of Almirall, AstraZeneca, Boehringer Ingelheim, Chiesi Farmaceutici, GlaxoSmithKline, and Novartis, and has been a consultant to ABC Farmaceutici and Chiesi Farmaceutici. Her department was funded by Novartis. Nicola A. Hanania has served as a consultant to Boehringer Ingelheim $\mathrm{GmbH}$, Sunovion Pharmaceuticals Inc., Novartis AG, Mylan Inc., Pearl Therapeutics Inc., and Pfizer Inc.. His institution received grant support on his behalf from GlaxoSmithKline plc, Boehringer Ingelheim GmbH, Pfizer Inc., Pearl Therapeutics Inc., and Sunovion Pharmaceuticals Inc. Mario Cazzola has participated as a faculty member and advisor in scientific meetings and courses under the sponsorship of Almirall, AstraZeneca, Biofutura, Boehringer Ingelheim, Chiesi Farmaceutici, GlaxoSmithKline, Menarini Group, Lallemand, Mundipharma, Novartis, Pfizer, Recipharm, Verona Pharma, and Zambon, and is or has been a consultant to ABC Farmaceutici, AstraZeneca, Chiesi Farmaceutici, Recipharm, Lallemand, Novartis, Ockham Biotech, Verona Pharma, and Zambon. His department was funded by Almirall, Boehringer Ingelheim, Novartis, and Zambon. Luigino Calzetta has participated as an advisor in scientific meetings under the sponsorship of Boehringer Ingelheim and Novartis, received non-financial support from AstraZeneca, a research grant partially funded by Chiesi
Farmaceutici, Boehringer Ingelheim, Novartis, and Almirall, and is or has been a consultant to ABC Farmaceutici, Recipharm, Zambon, Verona Pharma, and Ockham Biotech. His department was funded by Almirall, Boehringer Ingelheim, Chiesi Farmaceutici, Novartis, and Zambon.

Compliance with Ethics Guidelines. This article is based on reviews of current guidelines and literature and did not involve any studies with human participants or animals.

Open Access. This article is distributed under the terms of the Creative Commons Attribution-NonCommercial 4.0 International License (http://creativecommons.org/licenses/ by-nc/4.0/), which permits any noncommercial use, distribution, and reproduction in any medium, provided you give appropriate credit to the original author(s) and the source, provide a link to the Creative Commons license, and indicate if changes were made.

\section{REFERENCES}

1. Global Initiative for Asthma (GINA). Global strategy for asthma management and prevention. 2019. https://ginasthma.org/wp-content/uploads/2019/ 06/GINA-2019-main-report-June-2019-wms.pdf. Accessed 14 Oct 2019.

2. Reddel HK, Bateman ED, Becker A, Boulet LP, Cruz AA, Drazen JM, et al. A summary of the new GINA strategy: a roadmap to asthma control. Eur Respir J. 2015;46:622-39.

3. Sulaiman I, Greene G, MacHale E, Seheult J, Mokoka M, D'Arcy S, et al. A randomised clinical trial of feedback on inhaler adherence and technique in patients with severe uncontrolled asthma. Eur Respir J. 2018;51:1701126.

4. De Ferrari L, Chiappori A, Bagnasco D, Riccio AM, Passalacqua G, Canonica GW. Molecular phenotyping and biomarker development: are we on our way towards targeted therapy for severe asthma? Expert Rev Respir Med. 2016;10:29-38.

5. Brusselle GG, Maes T, Bracke KR. Eosinophils in the spotlight: eosinophilic airway inflammation in nonallergic asthma. Nat Med. 2013;19:977-9.

6. Israel E, Reddel HK. Severe and difficult-to-treat asthma in adults. N Engl J Med. 2017;377:965-76. 
7. Mori $\mathrm{Y}$, Iwasaki $\mathrm{H}$, Kohno $\mathrm{K}$, Yoshimoto $\mathrm{G}$, Kikushige Y, Okeda A, et al. Identification of the human eosinophil lineage-committed progenitor: revision of phenotypic definition of the human common myeloid progenitor. J Exp Med. 2009;206: 183-93.

8. Varricchi G, Bagnasco D, Borriello F, Heffler E, Canonica GW. Interleukin-5 pathway inhibition in the treatment of eosinophilic respiratory disorders: evidence and unmet needs. Curr Opin Allergy Clin Immunol. 2016;16:186-200.

9. Vatrella A, Fabozzi I, Calabrese C, Maselli R, Pelaia G. Dupilumab: a novel treatment for asthma. J Asthma Allergy. 2014;7:123-30.

10. Aleman F, Lim HF, Nair P. Eosinophilic endotype of asthma. Immunol Allergy Clin N Am. 2016;36: 559-68.

11. Parulekar AD, Diamant Z, Hanania NA. Role of T2 inflammation biomarkers in severe asthma. Curr Opin Pulm Med. 2016;22:59-68.

12. Khatry DB, Gossage DL, Geba GP, Parker JM, Jarjour NN, Busse WW, et al. Discriminating sputum-eosinophilic asthma: accuracy of cutoffs in blood eosinophil measurements versus a composite index, ELEN. J Allergy Clin Immunol. 2015;136:812-4 (e2).

13. Miranda C, Busacker A, Balzar S, Trudeau J, Wenzel SE. Distinguishing severe asthma phenotypes: role of age at onset and eosinophilic inflammation. J Allergy Clin Immunol. 2004;113:101-8.

14. Pavord ID, Korn S, Howarth P, Bleecker ER, Buhl R, Keene ON, et al. Mepolizumab for severe eosinophilic asthma (DREAM): a multicentre, doubleblind, placebo-controlled trial. Lancet. 2012;380: 651-9.

15. Kim JY, Sohn JH, Lee JH, Park JW. Obesity increases airway hyperresponsiveness via the TNF-alpha pathway and treating obesity induces recovery. PLoS One. 2015;10:e0116540.

16. European Medicines Agency. EMEA/H/C/000606. 2014. www.ema.europa.eu/en/documents/overview/ xolair-epar-summary-public_en.pdf. Accessed 8 Oct 2019.

17. US Food and Drug Administration. XOLAIR ${ }^{\circledR}$ (omalizumab) for injection, for subcutaneous use. Reference ID: 3955374. 2016. www.accessdata.fda. gov/drugsatfda_docs/label/2016/103976s5225lbl.pdf. Accessed 8 Oct 2019.

18. Busse W, Corren J, Lanier BQ, McAlary M, FowlerTaylor A, Cioppa GD, et al. Omalizumab, anti-IgE recombinant humanized monoclonal antibody, for the treatment of severe allergic asthma. J Allergy Clin Immunol. 2001;108:184-90.

19. European Medicines Agency. Xolair: European public assessment report.Product information. Amsterdam: European Medicines Agency; 2019.

20. Hanania NA, Alpan O, Hamilos DL, Condemi JJ, Reyes-Rivera I, Zhu J, et al. Omalizumab in severe allergic asthma inadequately controlled with standard therapy: a randomized trial. Ann Intern Med. 2011;154:573-82.

21. Hanania NA, Wenzel S, Rosen K, Hsieh HJ, Mosesova S, Choy DF, et al. Exploring the effects of omalizumab in allergic asthma: an analysis of biomarkers in the EXTRA study. Am J Respir Crit Care Med. 2013;187:804-11.

22. Busse W, Spector S, Rosen K, Wang Y, Alpan O. High eosinophil count: a potential biomarker for assessing successful omalizumab treatment effects. J Allergy Clin Immunol. 2013;132:485-6 (e11).

23. Busse WW, Morgan WJ, Gergen PJ, Mitchell HE, Gern JE, Liu AH, et al. Randomized trial of omalizumab (anti-IgE) for asthma in inner-city children. N Engl J Med. 2011;364:1005-15.

24. Matera MG, Calzetta L, Sanduzzi A, Page CP, Cazzola M. Effects of neuraminidase on equine isolated bronchi. Pulm Pharmacol Ther. 2008;21:624-9.

25. Kloepfer KM, Gern JE. Virus/allergen interactions and exacerbations of asthma. Immunol Allergy Clin N Am. 2010;30(553-63):vii.

26. Busse WW, Massanari M, Kianifard F, Geba GP. Effect of omalizumab on the need for rescue systemic corticosteroid treatment in patients with moderate-to-severe persistent IgE-mediated allergic asthma: a pooled analysis. Curr Med Res Opin. 2007;23:2379-86.

27. Bousquet J, Cabrera P, Berkman N, Buhl R, Holgate $S$, Wenzel S, et al. The effect of treatment with omalizumab, an anti-IgE antibody, on asthma exacerbations and emergency medical visits in patients with severe persistent asthma. Allergy. 2005;60:302-8.

28. Normansell R, Walker S, Milan SJ, Walters EH, Nair P. Omalizumab for asthma in adults and children. Cochrane Database Syst Rev. 2014;CD003559.

29. Ledford D, Busse W, Trzaskoma B, Omachi TA, Rosen K, Chipps BE, et al. A randomized multicenter study evaluating Xolair persistence of response after long-term therapy. J Allergy Clin Immunol. 2017;140:162-9 (e2). 
30. Vennera MDC, Sabadell C, Picado C, Spanish Omalizumab R. Duration of the efficacy of omalizumab after treatment discontinuation in 'real life' severe asthma. Thorax. 2018;73:782-4.

31. Singh H, Peters JI, Kaur Y, Maselli DJ, Diaz JD. Longterm evaluation of response to omalizumab therapy in real life by a novel multimodular approach: the real-life effectiveness of omalizumab therapy (REALITY) study. Ann Allergy Asthma Immunol. 2019;123:476-82.

32. Casale TB, Luskin AT, Busse W, Zeiger RS, Trzaskoma B, Yang M, et al. Omalizumab effectiveness by biomarker status in patients with asthma: evidence from PROSPERO, a prospective real-world study. J Allergy Clin Immunol. 2019;7:156-64.

33. Haldar P, Brightling CE, Hargadon B, Gupta S, Monteiro W, Sousa A, et al. Mepolizumab and exacerbations of refractory eosinophilic asthma. N Engl J Med. 2009;360:973-84.

34. US Food and Drug Administration. NUCALA (mepolizumab) for injection, for subcutaneous use. 2015. https://www.accessdata.fda.gov/drugsatfda docs/label/2017/125526s004lbl.pdf. Accessed 5 Dec 2019.

35. European Medicines Agency. Nucala. EMEA/H/C/ 003860-N/0027. 2015. https://www.ema.europa.eu/ en/documents/product-information/nucala-eparproduct-information_en.pdf. Accessed 5 Dec 2019.

36. Bousquet J, Brusselle G, Buhl R, Busse WW, Cruz AA, Djukanovic R, et al. Care pathways for the selection of a biologic in severe asthma. Eur Respir J. 2017;50:1701782.

37. GINA. Global Initiative for Asthma (GINA). Pocket guide for asthma management and prevention. 2019. https://ginasthma.org/wp-content/uploads/ 2019/04/GINA-2019-main-Pocket-Guide-wms.pdf. Accessed 5 Dec 2019.

38. National Institute for Health and Care Excellence (NICE). Mepolizumab for treating severe refractory eosinophilic asthma. 2017. http://www.nice.org. uk/guidance/ta431. Accessed 8 Oct 2019.

39. Ortega HG, Liu MC, Pavord ID, Brusselle GG, FitzGerald JM, Chetta A, et al. Mepolizumab treatment in patients with severe eosinophilic asthma. N Engl J Med. 2014;371:1198-207.

40. Bel EH, Wenzel SE, Thompson PJ, Prazma CM, Keene ON, Yancey SW, et al. Oral glucocorticoidsparing effect of mepolizumab in eosinophilic asthma. N Engl J Med. 2014;371:1189-97.

41. Lugogo N, Domingo C, Chanez P, Leigh R, Gilson MJ, Price RG, et al. Long-term efficacy and safety of mepolizumab in patients with severe eosinophilic asthma: a multi-center, open-label, phase IIIb study. Clin Ther. 2016;38:2058-70.

42. Khatri S, Moore W, Gibson PG, Leigh R, Bourdin A, Maspero J, et al. Assessment of the long-term safety of mepolizumab and durability of clinical response in patients with severe eosinophilic asthma. J Allergy Clin Immunol. 2018;143:1742-51.

43. Khurana S, Brusselle GG, Bel EH, FitzGerald JM, Masoli M, Korn S, et al. Long-term safety and clinical benefit of mepolizumab in patients with the most severe eosinophilic asthma: the COSMEX study. Clin Ther. 2019;41:2041-56.

44. US Food and Drug Administration. CINQAIR ${ }^{\circledR}$ (reslizumab) injection, for intravenous use. Reference ID: 3906489. 2016. www.accessdata.fda.gov/ drugsatfda_docs/label/2016/761033lbl.pdf. Accessed 8 Oct 2019 .

45. European Medicines Agency. EMEA/H/C/003912. 2016. www.ema.europa.eu/en/documents/overview/ cinqaero-epar-summary-public_en.pdf. Accessed 8 Oct 2019.

46. Corren J, Weinstein S, Janka L, Zangrilli J, Garin M. Phase 3 study of reslizumab in patients with poorly controlled asthma: effects across a broad range of eosinophil counts. Chest. 2016;150:799-810.

47. Castro M, Zangrilli J, Wechsler ME, Bateman ED, Brusselle GG, Bardin P, et al. Reslizumab for inadequately controlled asthma with elevated blood eosinophil counts: results from two multicentre, parallel, double-blind, randomised, placebo-controlled, phase 3 trials. Lancet Respir Med. 2015;3: 355-66.

48. Murphy K, Jacobs J, Bjermer L, Fahrenholz JM, Shalit Y, Garin M, et al. Long-term safety and efficacy of reslizumab in patients with eosinophilic asthma. J Allergy Clin Immunol. 2017;5:1572-81.

49. Kolbeck R, Kozhich A, Koike M, Peng L, Andersson CK, Damschroder MM, et al. MEDI-563, a humanized anti-IL-5 receptor alpha mAb with enhanced antibody-dependent cell-mediated cytotoxicity function. J Allergy Clin Immunol. 2010;125: 1344-53.

50. Pham TH, Damera G, Newbold P, Ranade K. Reductions in eosinophil biomarkers by benralizumab in patients with asthma. Respir Med. 2016;111:21-9.

51. US Food and Drug Administration. FASENRA (benralizumab) injection, for subcutaneous use. Reference ID: 4181236. 2019. www.accessdata.fda.gov/ drugsatfda_docs/label/2017/761070s000lbl.pdf. Accessed 8 Oct 2019. 
52. European Medicines Agency. EMEA/H/C/4433. 2019. www.ema.europa.eu/en/documents/overview/ fasenra-epar-medicine-overview_en.pdf. Accessed 8 Oct 2019.

53. Bleecker ER, FitzGerald JM, Chanez P, Papi A, Weinstein SF, Barker P, et al. Efficacy and safety of benralizumab for patients with severe asthma uncontrolled with high-dosage inhaled corticosteroids and long-acting beta2-agonists (SIROCCO): a randomised, multicentre, placebo-controlled phase 3 trial. Lancet. 2016;388:2115-27.

54. FitzGerald JM, Bleecker ER, Nair P, Korn S, Ohta K, Lommatzsch $\mathrm{M}$, et al. Benralizumab, an anti-interleukin-5 receptor alpha monoclonal antibody, as add-on treatment for patients with severe, uncontrolled, eosinophilic asthma (CALIMA): a randomised, double-blind, placebo-controlled phase 3 trial. Lancet. 2016;388:2128-41.

55. Nair P, Wenzel S, Rabe KF, Bourdin A, Lugogo NL, Kuna $\mathrm{P}$, et al. Oral glucocorticoid-sparing effect of benralizumab in severe asthma. $\mathrm{N}$ Engl J Med. 2017;376:2448-58.

56. Busse WW, Bleecker ER, FitzGerald JM, Ferguson GT, Barker P, Sproule S, et al. Long-term safety and efficacy of benralizumab in patients with severe, uncontrolled asthma: 1-year results from the BORA phase 3 extension trial. Lancet Respir Med. 2019;7: 46-59.

57. European Medicines Agency. Dupinex: EMEA/H/C/ 004390. 2018. https://www.ema.europa.eu/en/docu ments/product-information/dupixent-epar-productinformation_en.pdf. Accessed 5 Dec 2019.

58. US Food and Drug Administration. DUPIXENT ${ }^{\circledR}$ (dupilumab) injection, for subcutaneous use. 2017. https://www.accessdata.fda.gov/drugsatfda_docs/ label/2018/761055s007lbl.pdf. Accessed 5 Dec 2019.

59. Wenzel S, Castro M, Corren J, Maspero J, Wang L, Zhang B, et al. Dupilumab efficacy and safety in adults with uncontrolled persistent asthma despite use of medium-to-high-dose inhaled corticosteroids plus a long-acting beta 2 agonist: a randomised double-blind placebo-controlled pivotal phase $2 \mathrm{~b}$ dose-ranging trial. Lancet. 2016;388:31-44.

60. Castro M, Corren J, Pavord ID, Maspero J, Wenzel S, Rabe KF, et al. Dupilumab efficacy and safety in moderate-to-severe uncontrolled asthma. N Engl J Med. 2018;378:2486-96.

61. Rabe KF, Nair P, Brusselle G, Maspero JF, Castro M, Sher L, et al. Efficacy and safety of dupilumab in glucocorticoid-dependent severe asthma. N Engl J Med. 2018;378:2475-85.
62. Corren J, Castro M, Chanez P, Fabbri L, Joish VN, Amin N, et al. Dupilumab improves symptoms, quality of life, and productivity in uncontrolled persistent asthma. Ann Allergy Asthma Immunol. 2019;122:41-9.

63. Corren J, Castro M, Ford LB, Bernstein JA, Jayawardena S, Maroni J, et al. Dupilumab improves asthma outcomes irrespective of frequency of previous asthma exacerbation history. Ann Allergy Asthma Immunol Off Publ Am Coll Allergy Asthma Immunol. 2019;123:222-4.

64. Corren J, Castro M, O'Riordan T, Hanania NA, Pavord ID, Quirce S, et al. Dupilumab efficacy in patients with uncontrolled, moderate-to-severe allergic asthma. J Allergy Clin Immunol. Forthcoming 2020.

65. Corren J, Parnes JR, Wang L, Mo M, Roseti SL, Griffiths JM, et al. Tezepelumab in adults with uncontrolled asthma. N Engl J Med. 2017;377: 936-46.

66. Moher D, Shamseer L, Clarke M, Ghersi D, Liberati A, Petticrew M, et al. Preferred reporting items for systematic review and meta-analysis protocols (PRISMA-P) 2015 statement. Syst Rev. 2015;4:1.

67. Chung KF, Wenzel SE, Brozek JL, Bush A, Castro M, Sterk PJ, et al. International ERS/ATS guidelines on definition, evaluation and treatment of severe asthma. Eur Respir J. 2014;43:343-73.

68. Manka LA, Wechsler ME. Selecting the right biologic for your patients with severe asthma. Ann Allergy Asthma Immunol. 2018;121:406-13.

69. Bourdin A, Husereau D, Molinari N, Golam S, Siddiqui $\mathrm{MK}$, Lindner $\mathrm{L}$, et al. Matching-adjusted indirect comparison of benralizumab versus interleukin-5 inhibitors for the treatment of severe asthma: a systematic review. Eur Respir J. 2018;52: 1801393.

70. Casale TB, Pacou M, Mesana L, Farge G, Sun SX, Castro M. Reslizumab compared with benralizumab in patients with eosinophilic asthma: a systematic literature review and network meta-analysis. J Allergy Clin Immunol. 2019;7:122-30.

71. Busse W, Chupp G, Nagase H, Albers FC, Doyle S, Shen Q, et al. Anti-IL-5 treatments in patients with severe asthma by blood eosinophil thresholds: indirect treatment comparison. J Allergy Clin Immunol. 2019;143:190-200.

72. Edris A, De Feyter S, Maes T, Joos G, Lahousse L. Monoclonal antibodies in type 2 asthma: a systematic review and network meta-analysis. Respir Res. 2019;20:179. 
73. Calzetta L, Matera MG, Rogliani P. Monoclonal antibodies in severe asthma: is it worth it? Expert Opin Drug Metab Toxicol. 2019;15:517-20.

74. Perez de Llano LA, Cosio BG, Domingo C, Urrutia I, Bobolea I, Valero A, et al. Efficacy and safety of reslizumab in patients with severe asthma with inadequate response to omalizumab: a multicenter, open-label pilot study. J Allergy Clin Immunol. 2019;7:2277-83.

75. Albers F, Liu MC, Chipps BE, Chapman KR, Muñoz $\mathrm{X}$, Bergna $\mathrm{M}$, et al. Therapeutic switch from omalizumab to mepolizumab in patients with uncontrolled severe eosinophilic asthma: treatment effect by prior omalizumab treatment duration. J Allergy Clin Immunol. 2019;143:AB102.

76. Bagnasco D, Menzella F, Caminati M, Caruso C, Guida G, Bonavia M, et al. Efficacy of mepolizumab in patients with previous omalizumab treatment failure: real life observation. Allergy. 2019;74: 2539-41.

77. Kavanagh J, Green L, Fernandes M, Roxas C, Kent B, Jackson D, et al. Response to benralizumab after sub-optimal response to mepolizumab in oral corticosteroid dependent severe eosinophilic asthma. Am J Respir Crit Care Med. 2019;199:A2675. https://doi.org/10.1164/ajrccm-conference.2019. 199.1_MeetingAbstracts.A2675.

78. Carlo L, Francesco M, Giovanni P. Long-term responsiveness to mepolizumab after failure of omalizumab and bronchial thermoplasty: two triple-switch case reports. Respir Med Case Rep. 2019;29:100967.

79. Ortega G, Tongchinsub P, Carr T. Combination biologic therapy for severe persistent asthma. Ann Allergy Asthma Immunol. 2019;123:309-11.
80. Cazzola M, Calzetta L, Rogliani P, Matera MG. The challenges of precision medicine in COPD. Mol Diagn Ther. 2017;21:345-55.

81. Busse WW, Maspero JF, Rabe KF, Papi A, Wenzel SE, Ford LB, et al. Liberty Asthma QUEST: phase 3 randomized, double-blind, placebo-controlled, parallel-group study to evaluate dupilumab efficacy/safety in patients with uncontrolled, moderate-to-severe asthma. Adv Ther. 2018;35:737-48.

82. European Medicines Agency. Xolair: EMEA/H/C/ 000606-II/0093. 2005. https://www.ema.europa.eu/ en/documents/product-information/xolair-eparproduct-information_en.pdf. Accessed 5 Dec 2019.

83. US Food and Drug Administration. XOLAIR ${ }^{\circledR}$ Omalizumab. 2003. https://www.accessdata.fda. gov/drugsatfda_docs/label/2003/omalgen062003LB. pdf. Accessed 5 Dec 2019.

84. European Medicines Agency. Cinqaero: EMEA/H/C/ 003912-IAIN/0023. 2016. https://www.ema.europa. eu/en/documents/product-information/cinqaeroepar-product-information_en.pdf. Accessed 5 Dec 2019.

85. US Food and Drug Administration. CINQAIR (reslizumab) injection, for intravenous use. 2016. https://www.accessdata.fda.gov/drugsatfda_docs/label/ 2016/761033lbl.pdf. Accessed 5 Dec 2019.

86. European Medicines Agency. Fasenra: EMEA/H/C/ 004433-II/0014/G. 2018. https://www.ema.euro pa.eu/en/documents/product-information/fasenraepar-product-information_en.pdf. Accessed 5 Dec 2019.

87. US Food and Drug Administration. Fasenra (benralizumab) $30 \mathrm{mg} / \mathrm{ml}$ injection. 2017. https://www. accessdata.fda.gov/drugsatfda_docs/nda/2017/761 070Orig1s000TOC.cfm. Accessed 5 Dec 2019. 